\title{
Transfusão/anemia associada à enterocolite necrosante
}

\section{Blood cell transfusion / anemia associated to necrotizing enterocolitis}

\author{
Adauto Dutra Moraes Barbosa ${ }^{1}$ \\ Universidade Federal Fluminense
}

Desde a última década, ${ }^{1}$ a associação entre transfusão de concentrado de hemácias (TCH) e a ocorrência de enterocolite necrosante (ECN) tem sido alvo de investigações constantes. Cerca de um terço dos casos de ECN em recém-nascidos de muito baixo peso ocorrem entre 24-48 horas após a TCH e o risco é maior quando aqueles recém-nascidos prematuros apresentam anemia grave. ${ }^{2}$ Em virtude disso, a relação transfusão e ECN tem sido denominada transfusão/anemia associada à ECN. ${ }^{2}$

A etiologia da ECN tem sido postulada como multifatorial e ainda não esclarecida, assim como sua fisiopatologia e profilaxia. ${ }^{3}$ Sabe-se que, além da anemia grave e da hemotransfusão, condições que predisponham o intestino à isquemia - tais como cardiopatia congênita e pré-eclâmpsia materna com insuficiência vascular placentária - seriam fatores adversos imputados na gênese da ECN. ${ }^{4}$

Fisiopatologicamente, permanece incerto se após uma translocação bacteriana e/ou de seus produtos frente a uma barreira intestinal imunologicamente tênue ocorreria, a priori, uma resposta inflamatória exagerada e, a posteriori, uma lesão da mucosa. Recentemente, descobriu-se que o desenvolvimento inadequado da microvasculatura intestinal, que tem a importante participação do fator de crescimento endotelial vascular (VEGF) e da via de sinalização do receptor VEGF-2, ocasionariam alterações no fluxo sanguíneo intestinal. ${ }^{4}$

Os dois casos descritos e comentados por Lino e colaboradores, publicados neste fascículo da Revista de Pediatria SOPERJ, compõem exemplos clássicos que trazem à luz do conhecimento atual o que se vê na prática diária. Para o neonatologista, transfundir concentrado de hemácias em mais de $90 \%$ dos prematuros de muito baixo peso é um procedimento comum, que passou, no entanto, a centro de inúmeros cuidados que incluem benefícios e riscos a curto e longo prazo.

Evidências recentes ligadas às respostas adaptativas pós- $\mathrm{TCH}^{5}$ em prematuros com diferentes níveis de anemia e diferentes idades gestacionais e pós-natais têm sido importantes motivos de investigação para se seguir critérios cautelosos e limiares oportunos de $\mathrm{TCH}$, a fim de se contribuir com a redução do desenvolvimento da ECN. ${ }^{6}$

\section{REFERÊNCIAS}

1 Mally P, Golombek SG, Mishra R, Nigam S, Mohandas K, Depalhma $\mathrm{H}$ et al. Association of necrotizing enterocolitis with elective packed red blood cell transfusions in stable, growing, premature neonates. Am J Perinatol. 2006;23(8):451-8.

2 Maheshwari A, Patel RM, Christensen RD. Anemia, red blood cell transfusions, and necrotizing enterocolitis. Seminars in Pediatric Surgery. 2018;27(1):47-51. DOI: http://dx.doi. org/10.1053/j.sempedsurg.2017.11.009

3 Faraday C, Hamad S, Jones KD, Sim K, Cherian S, James A et al. Characteristics and incidence of transfusion-associated necrotizing enterocolitis in the UK. J Matern Fetal Neonatal Med. 2018;1:1-6. DOI: http://dx.doi.org/10.1080/14767058.201 8.1494147

4 Bowker RM, Yan X, De Plaen IG. Intestinal microcirculation and necrotizing enterocolitis: the vascular endothelial growth factor system. Semin Fetal Neonatal Med. 2018. DOI: http:// dx.doi.org/10.1016/j.siny.2018.08.008

5 Kalteren WS, Kuik SJ, Van Braeckel KNJA, Hulscher JBF, Bos AF, Kooi EMW et al. Red blood cell transfusions affect intestinal and cerebral oxygenation differently in preterm infants with and without subsequent necrotizing enterocolitis. Am J Perinatol. 2018;35(11):1031-37. DOI: http://dx.doi. org $/ 10.1055 / \mathrm{s}-0038-1636532$

6 Howarth C, Banerjee J, Aladangady N. Red blood cell transfusion in preterm infants: current evidence and controversies. Neonatology. 2018;114(1):7-16. DOI: http:// dx.doi.org/10.1159/000486584 